\title{
Vibration assisted drilling of CFRP/metal stacks at low frequencies and high amplitudes
}

\author{
Friedrich Bleicher ${ }^{1} \cdot$ Gerhard Wiesinger $^{1} \cdot$ Christoph Kumpf $^{1} \cdot$ Daniel Finkeldei $^{1} \cdot$ Christian Baumann $^{1}$. \\ Christoph Lechner ${ }^{1}$
}

Received: 21 November 2017 / Accepted: 2 March 2018 / Published online: 21 March 2018

(c) The Author(s) 2018

\begin{abstract}
In many applications of automotive and aircraft industries the use of material combinations such as compound materials made from carbon fiber reinforced plastics (CFRP) and metal materials like steel, titanium or aluminum alloys is significantly increasing. For these industries, the lightweight and mechanical properties of the reinforced plastic materials gain more and more importance. When machining material combinations, a number of distinctive material related effects occur and hamper the straight-forward implementation of machining processes. These effects mainly derive from the distinctive chipping behavior of the material combination caused by the different material characteristics. Thus, the drilling process of CFRP/metal stacks is to be regarded as a challenging task due to the requirements of machining efficiency and quality aspects. In this regard, vibration assisted drilling at low frequencies but high amplitudes opens up significant opportunities for improvements of the machining processes. The feed rate is superimposed by a controlled harmonic motion in order to create an intermittent cutting state. The potential of vibration assisted drilling lies in the reduction of cutting forces and tool wear.
\end{abstract}

Keywords Composite $\cdot$ Fibre reinforced plastic $\cdot$ Drilling $\cdot$ Vibration

\section{Introduction}

Fiber reinforced plastics are mainly used for components of the automotive and aircraft industries. Lightweight parts and improved mechanical properties of these components play an essential role and are of imminent importance for products of these industries. As a result, the use of compound materials made from carbon fiber reinforced plastics (CFRP) and metals like steel, titanium or aluminum alloys are increasing [1,2]. For modern aircrafts such as the Boeing 787 or the Airbus A350, in which the use of CFRP material amounts to approximately $50 \%$ of the overall mass, panels are arranged in sandwich-type stacking with CFRP and metals like aluminum or titanium [1, 3, 4]. Particularly in conjunction points of assemblies, the use of steel metal inserts helps to realize holes for screws or rivets with an improved transmission of loads into the CFRP component area.

Gerhard Wiesinger

wiesinger@ift.at

1 IFT, Institute for Production Engineering and Laser Technology, TU Wien, Vienna, Austria
These combined materials in a stacked configuration are much lighter than advanced metallic structures and provide excellent mechanical properties such as high tensile strength and stiffness as well as corrosion resistance [3]. The challenge with these stacked materials is to manufacture costlimited and high-quality products in serial production [1]. For joining and assembly, numerous holes are to be produced running through the entire material stack, which requires a stable drilling process of both materials in a single procedure [3]. Brinksmeier highlights in [5], that the drilling process of CFRP/metal stacks is a challenging task because of the changing machining properties. Besides the use of specific process parameters for both materials, machining of CFRP requires sharp cutting edges and special tool geometries. These sharp cutting edges lead to high tool stresses at the cutting edge and advanced tool wear in machining the metal component [6]. In common applications, dry machining is applied in cutting of CFRP materials and thus high temperatures occur during the metal cutting process expediting the tool wear [7]. Burr formation, especially at the exit position of the hole, and degradation of the machined surface quality are typical causes of failure [8]. On the one hand, the cutting parameters can be adopted according to the actual 
material layer when machining both materials as stacks [9]. On the other hand compromises in the tool micro- and macro-geometry as well as in the tool material and coatings have to be made. Particularly for CFRP/titanium or CFRP/ steel, excessive tool wear is one of the most important topics, which needs to be improved [10].

In addition, defects associated with CFRPs like delamination, matrix burnout, splintering and fraying are of major safety and economic concerns for the manufacturers [11]. To overcome these issues, several investigations and approaches in the drilling of CFRP were made. A first approach to fiber cutting mechanisms in orthogonal cutting shows that fiber orientation has a significant effect on surface quality $[12,13]$. A reduction of delamination was observed when a decrease in the feed force takes place [14-16]. For fiber reinforced plastics more efficient drill designs such as saw drills, candlestick drills and abrasive tools were tested. These geometries cannot fulfil the demands of CFRP/titanium and CFRP/steel stack drilling [1]. For metallic and composite specifications, conventional twist drill geometries are more appropriate and must be improved [10].

Hence, the interest to overcome the challenges of conventional drilling is rising. A recent and promising technique is vibration assisted drilling (VAD), which provides significant advantages in terms of productivity and tolerances of the drilled holes [17]. The feed rate is superimposed by a controlled harmonic motion in order to create an intermittent cutting state. Bleicher and Kumpf show in [18], that the machining process can be influenced by variation of the frequency and amplitude, which opens up significant opportunities for process improvements. Using this technology, difficult-to-cut materials like brittle-hard materials (i.e. ceramics), fiber composites or high-strength metal alloys can be machined in a more productive way. The choice of vibrational parameters can be used to achieve effects similar to trochoid or helical processing $[18,19]$. Because of the intermitted cut, cutting forces, tool wear as well as cutting temperatures can be decreased [19-23]. Additionally, the vibrational movement can lead to a higher quality of the produced surfaces [24].

For realizing the vibrational motions, different types of actuators are used. The known actuator systems comprise of piezo actuators for high frequency and low amplitude actuation or different designs based on electro-mechanic systems for small and medium sized amplitudes and frequencies. Furthermore, mechanically or hydraulically operated systems are known, which are typically working in a low frequency range but offering high amplitudes. Figure 1 shows an overview of the performance and operational range of different systems as they are known from literature or experimental investigations. As depicted in the graph,

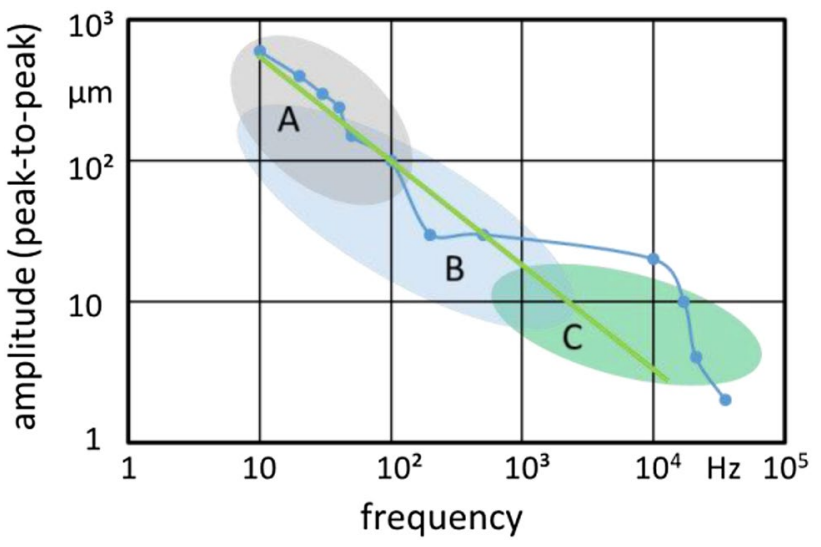

Fig. 1 Overview of actuator types with respect to typical performance and operational range of use: (A) mechanical, hydraulic systems, (B) electro-mechanical actuators, (C) piezo actuators

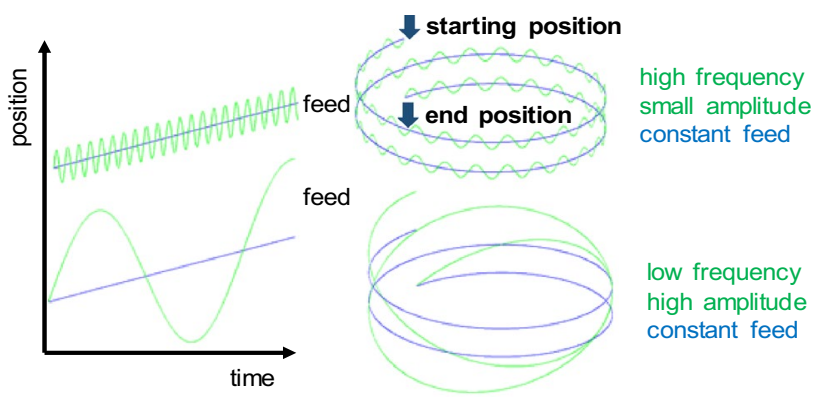

Fig. 2 Superposition of the feed movement (blue) with a harmonic oscillation (green) [18]

an exponential characteristic of frequency and amplitude range can be determined and approximated by the following equation.

$A=A_{\text {ref }} \cdot\left(\frac{F}{F_{\text {ref }}}\right)^{-a}$

The resulting amplitude $A$ of actuators is correlating to the frequency $F$. By the use of a reference amplitude $A_{\text {ref }}=$ $100 \mu \mathrm{m}$ and a reference frequency of $F_{r e f}=100 \mathrm{~Hz}$ the process amplitude can be estimated by the use of an exponent factor $\mathrm{a}=0.7$.

However, with currently available actuating devices mainly two types of modes, high frequency and small amplitude as well as low frequency and high amplitude, are used for the VAD-process (see Fig. 2). In addition to the constant feed rate, the tool is engaging and retracting because of the interfered harmonic motion. The chip thickness varies in a range of a maximum value down to zero, when the cutting edge moves completely out of the material; an active chip breakage occurs $[23,24]$. In both, research and industry, 
many applications of vibration assisted machining are currently realized in the high frequency range at about $20 \mathrm{kHz}$ or even higher (ultrasonic, see Fig. 1 area C).

The US-systems use resonance effects of sonotrodes, which are located in the spindle rotor or in the tool-holder, respectively. The sonotrode is activated in their resonance frequency for amplifying the real stroke of the actuator. The similarity for all of these systems is the capability to generate low amplitudes in a range of a few micrometers [23]. In contrast, the other approach of vibration assistance at low frequency and high amplitude mode results in significant improvements of hole quality and tool life [25]. However, current high end actuator systems which are operating in this mode will be discussed in the following.

\section{Actuator systems for low frequency and high amplitude}

In contrast to the high frequency type of spindles, the low frequency but high amplitude systems consist of an actuator which moves the spindle rotor or even the entire main spindle. Hence, these systems are designed for higher acceleration forces.

\subsection{Spindle unit with magnetic bearings}

Figure 3 shows the design of a spindle unit from the company LTI Motion. The vibrations are generated by active magnetic bearings which allow a three dimensional movement of the spindle rotor in six degrees of freedom. This makes it possible to realize drilling operations like trochoid or helical processing in combination with VAD. The system has a rated power of about $6.5 \mathrm{~kW}$ at a rotational speed of $12,000 \mathrm{rpm}$. The maximum speed ranges up to $60,000 \mathrm{rpm}$.

The use of active magnetic bearings offers advantages like a higher spindle service life time due to the contact free support. However, this working principle comes along with challenges related to dynamic control and process stability.

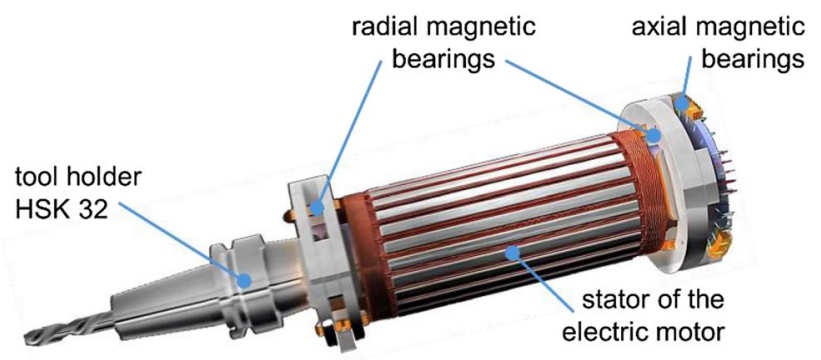

Fig. 3 Design of spindle unit with magnetic bearings (LTI)

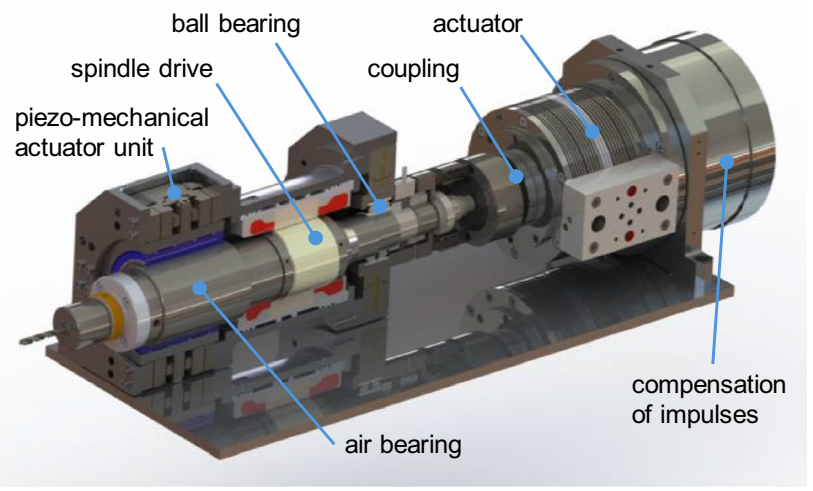

Fig. 4 Design of the hydraulically and piezo-mechanically actuated spindle unit

\subsection{Spindle unit with hydraulic actuator}

As part of previous research work, a three axis activated spindle unit was developed including a piezo electrically and hydraulically actuated spindle system for three dimensional rotor movement and vibration assistance in machining (see Fig. 4). The spindle rotor suspension technique is based on air bearing technology. The high-speed spindle is driven by a synchronous motor with a rated power of $6.5 \mathrm{~kW}$. The water-cooled drive shows a rated speed of $9000 \mathrm{rpm}$ and a maximum speed of 30,000 rpm. The spindle is installed in a horizontal position with a total of three bearing points: an air bearing at the front spindle flange, two ball bearing units at the rear end of the spindle and the mechanical connection between the actuator system and the spindle rotor.

This constructive design helps to realize a stroke of the vibration in axial direction. The axial vibration movement of the spindle, in the machine tool coordinate system equal to $\mathrm{Z}$, is generated by the hydraulic actuator system. As a result, high process forces can be applied while using a relatively small constructive space for the design of the actuator. The size and mass of the overall spindle unit are finally essential

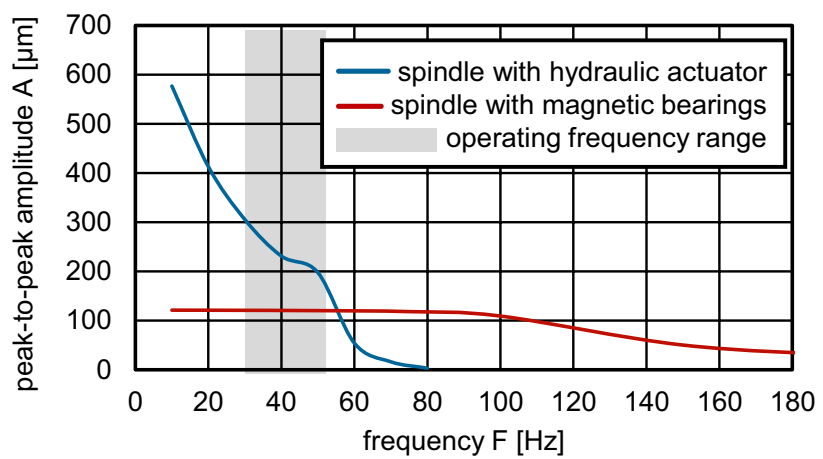

Fig. 5 Comparison of the axial oscillation of a spindle with magnetic bearings (LTI) and a spindle with hydraulic actuator (IFT) 
for the use in machine tools. The movement in each radial direction, $\mathrm{X}$ and $\mathrm{Y}$, is generated by the piezo-mechanical actuators including flexure hinges.

Both spindle systems described above are capable to create a three dimensional vibration assistance of machining processes with radial vibrations at peak-to-peak amplitudes of up to $50 \mu \mathrm{m}$. Figure 5 shows a comparison of the axial motion which points out the relationship between amplitude and frequency. The spindle with magnetic bearings operates at lower frequencies with a maximum amplitude of around $120 \mu \mathrm{m}$. At a frequency range higher than $100 \mathrm{~Hz}$ the amplitude is constantly decreasing and reaches, e.g., $20 \mu \mathrm{m}$ at approximately $\mathrm{f}=225 \mathrm{~Hz}$. The hydraulic actuated spindle system generally operates in a range of up to $200 \mathrm{~Hz}$ depending on the hydraulic valve used in the actuator. During the experimental tests, frequencies were limited to $80 \mathrm{~Hz}$ by the given setup with the implemented hydraulic components (see Fig. 5).

However, for the possible frequency range comparably high amplitudes of up to more than $500 \mu \mathrm{m}$ can be achieved. In the range of $30-50 \mathrm{~Hz}$, which is used during the experimental tests, the peak-to-peak amplitude shows values of approximately 200 up to $300 \mu \mathrm{m}$. Due to the achievable amplitudes the latter spindle unit was used for the experimental tests in drilling CFRP/metal stacks.

\section{Experimental setup}

A material combination made of CFRP and C45E is used for the machining experiments. The specimens of this stack material combination are dimensioned in a length of up to $150 \mathrm{~mm}$ and a width of $110 \mathrm{~mm}$ by a total thickness of $7 \mathrm{~mm}$ ( $3 \mathrm{~mm}$ for the metal layer and $4 \mathrm{~mm}$ for the CFRP material). $\mathrm{C} 45 \mathrm{E}$ was chosen because this type of material is well known as a standard test material in cutting research. The steel is heat-treatable with a tensile strength up to $850 \mathrm{MPa}$ and a hardness of $255 \mathrm{HB}$. The CFRP material is made of a twill 2/2 textured panel (prepreg-material SIGRATEX

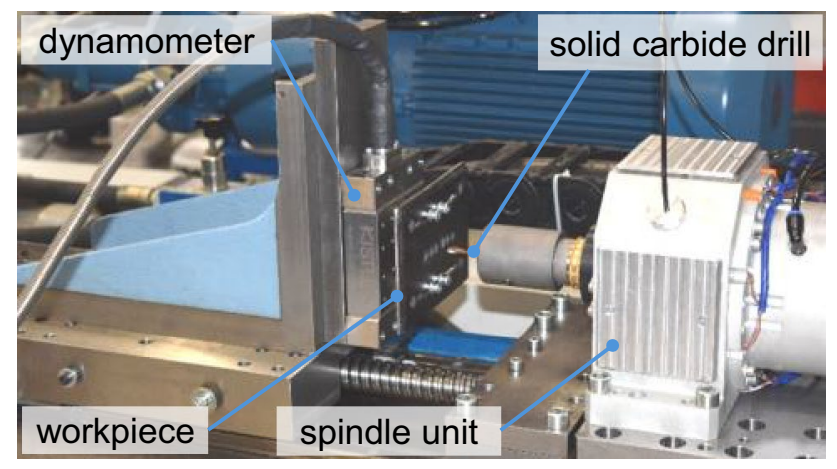

Fig. 6 Experimental setup with hydraulic actuated spindle
PREPREG CE 8201-200-45S). Two types of fibers are applied with a diameter of $7 \mu \mathrm{m}$. The warp thread is a PyrofilTM TR30S of MITSUBISHI and the weft thread is set to a Toray T300. The texture has a grade of 5 fibers per $\mathrm{cm} \mathrm{CF}$ 3K 200 tex.

The drilling tests were carried out on a drilling test stand with NC-controlled axis motion (see Fig. 6). The specimens are mounted directly on the fixture platform (angle plate) with a KISTLER 9129AA dynamometer using spacer blocks.

Sandvik CoroDrill ${ }^{\circledR} 460-\mathrm{XM}$ shank drills of diameter $6.35 \mathrm{~mm}$ useable up to a length/diameter ratio $1 / \mathrm{D}=3.15$ were used for the investigation (HC, TiAlN-coating). The drill geometry has a rake angle $\gamma=21.7^{\circ}$ and a cutting edge rounding of about $r_{\beta}=52 \mu \mathrm{m}$.

In order to be able to examine the effects of the different vibration parameters on the drilling process, all other parameters for the experiments were kept constant. The excitation takes place with an approximate sinusoidal vibration stroke in the feed direction. Thus, the feed rate can be interpreted as harmonically oscillating. The whole study was conducted without lubrication (dry machining). At the beginning, feed forces under VAD and CD were investigated. During the cutting tests the cutting speed $\mathrm{v}_{\mathrm{c}}$ was set to values of 40 and $80 \mathrm{~m} / \mathrm{min}$, additionally the feed was selected with 0.1 and $0.15 \mathrm{~mm} / \mathrm{rev}$. The spindle vibration was applied at frequencies of 25 up to $50 \mathrm{~Hz}$ at an amplitude of about $130 \mu \mathrm{m}$.

\section{Results of the drilling tests}

Applying vibrations on the drilling process aims to improve the chip formation in order to achieve an appropriate chip breakage, to reduce the cutting forces and thus to improve the tool life time.

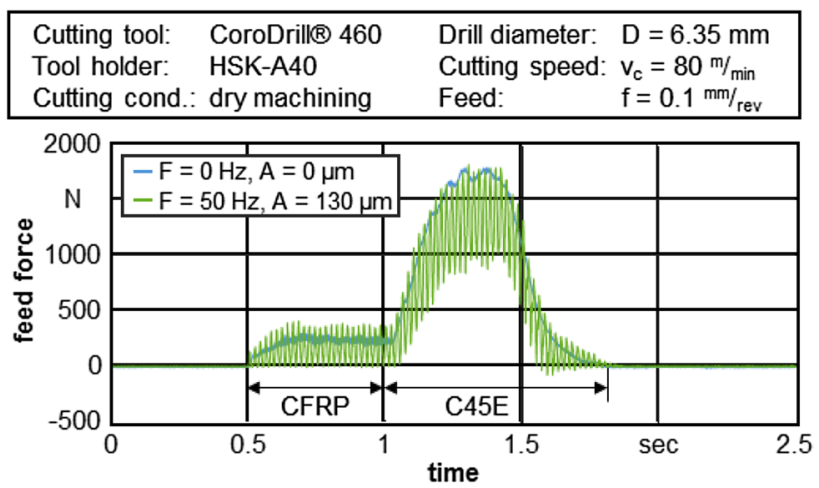

Fig. 7 Feed force for CD (blue) and VAD (green) 


\subsection{Force measurement}

In order to investigate the influence of low frequencies and high amplitudes on the cutting force, drilling tests have been performed on the above mentioned test stand. As Fig. 7 depicts, the feed force of $\mathrm{CD}$ is forming an upper envelope of the VAD feed force (blue line). For these investigations, the spindle vibration was set to a frequency of $50 \mathrm{~Hz}$, which comes up with an amplitude of $130 \mu \mathrm{m}$. In addition, the cutting speed $v_{c}$ was defined at the value of $80 \mathrm{~m} / \mathrm{min}$ and a feed of $0.1 \mathrm{~mm} / \mathrm{rev}$ was finally used.

The results show that especially the maximum values of the feed force for VAD stays inside the envelope of force values during the $\mathrm{CD}$. While machining the CFRP material, the peaks of feed force in VAD are slightly higher compared to the values of $C D$. Nevertheless, the average feed force can be significantly reduced by VAD. Regarding the higher maximum feed force values for VAD of the CFRP, an interpretation can be derived from the effect of an higher specific cutting force exponent $m_{c}$. López de Lacalle et al. defined this specific cutting force exponent in a range of 0.232-0.629 for a distinctive CFRP material [26]. In this regard, C45E steel only has a specific cutting force exponent of 0.22 . Thus, when drilling with and without vibration assistance, there is a slightly different behavior in the feed-and cutting forces-of C45E and CFRP detected.

\subsection{Chip classification}

A classification for different types of chip shapes at the mechanical processing of metals is given in [27]. Categories 1-4 are inconvenient since the chips do not break and have a high volume. Therefore, the risk for the process stability, damages to the machine tool and the danger of injury for the machine operator is very high. The chips of categories 5-8 are more convenient because of the periodic chip break. Figure 8 depicts, that e.g., at a cutting speed of $80 \mathrm{~m} / \mathrm{min}$ and a feed of $0.1 \mathrm{~mm} / \mathrm{rev}$ the C45E chips with VAD displays characteristics from categories 5-8. Hence, it can be demonstrated that VAD improves the chip building compared to drilling without vibration assistance.

Both VAD related effects including the reduction of average feed force (affects the overall process force including cutting force) and the improved chip breakage lead to advantageous cutting conditions, which help to increase the tool life time and the hole quality.

\subsection{Tool wear analysis}

The tool wear characterization was done by using a cutting speed of $v_{c}=40 \mathrm{~m} / \mathrm{min}$ and a feed of $\mathrm{f}=0.15 \mathrm{~mm} / \mathrm{rev}$.

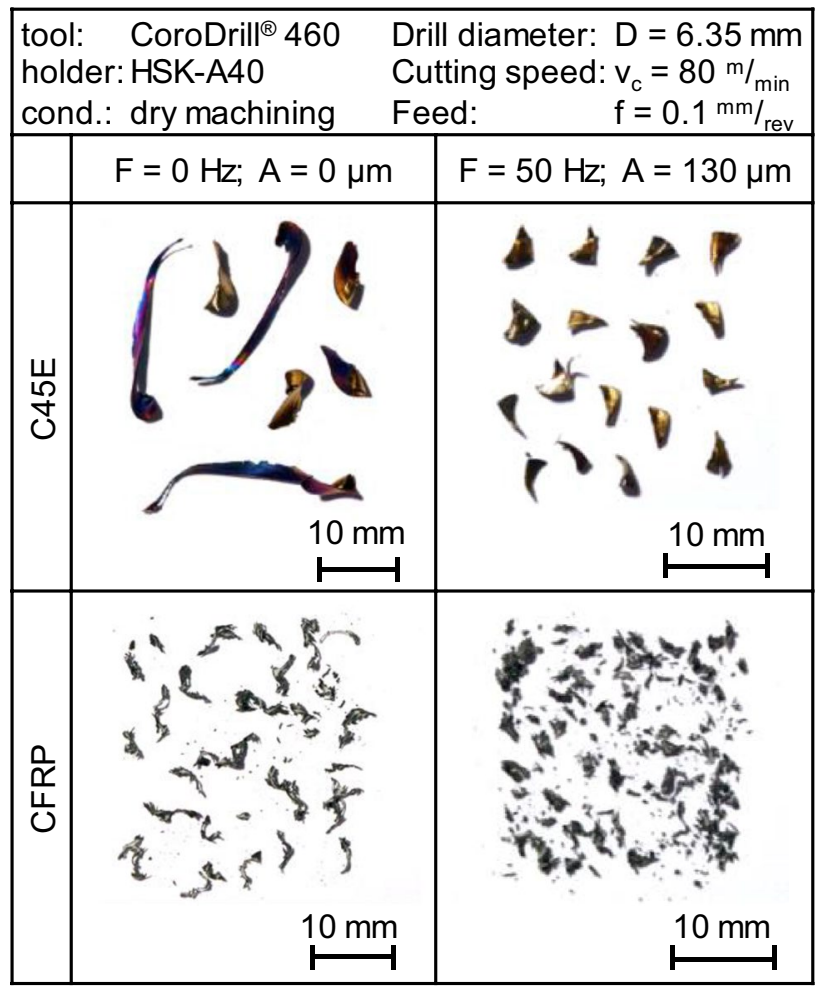

Fig. 8 Chips for CD (left) and VAD (right)

\begin{tabular}{|llll|}
\hline Cutting tool: & CoroDrill ${ }^{\otimes} 460$ & Drill diameter: & $D=6.35 \mathrm{~mm}$ \\
Tool holder: & HSK-A40 & Cutting speed: & $v_{c}=40 \mathrm{~m} / \mathrm{min}$ \\
Cutting cond.: & dry machining & Feed: & $\mathrm{f}=0.15 \mathrm{~mm} / \mathrm{rev}$ \\
\hline
\end{tabular}

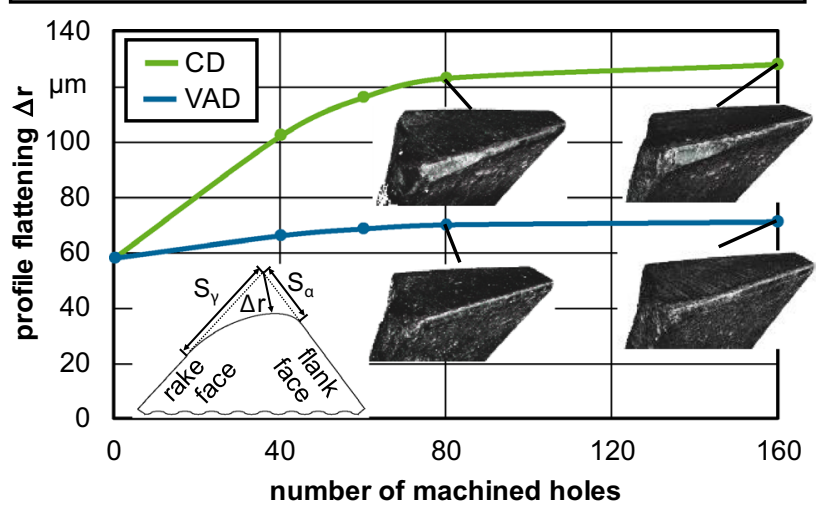

Fig. 9 Development of tool wear for conventional drilling (CD) and vibration assisted drilling (VAD)

Conventional drilling without oscillation was carried out as reference test. When machining with and without oscillation, the general wear mechanism in cutting CFRP and C45E steel is flank wear paired with an abrasive regression of the cutting edge. Figure 9 presents the development of tool wear over drilling 160 holes, describing the wear status by the use of the profile flattening $\Delta \mathrm{r}$ as a measured parameter. It 
can be revealed that the VAD process comes along with a significantly improved and more stable wear behavior.

\subsection{Hole quality evaluation}

The use of CFRP stack materials focus on highly loaded and lightweight applications. Hence, the fracture behavior and fatigue strength of the components is of major interest. Drilling CFRP/metal compounds shows different aspects of quality criteria. The resulting surface roughness is an important parameter, which describes not only the direct influence of the cutting tool on the hole wall but also the tool dynamic stability and the chip evacuation. Long chips can be regarded as leverages with a certain effective section modulus. Thus, longer chips can affect the hole wall by scratching and eroding, especially the CFRP. In Fig. 10 the surface quality measuring results for selected holes are summarized.

As the figure depicts, VAD helps to reduce the roughness values $\mathrm{Ra}$ and $\mathrm{Rz}$ in particular when machining the CFRP material at higher cutting speeds. Due to additional positive effects on drilling $\mathrm{C} 45 \mathrm{E}$, the evaluation of the measured surface quality shows a correlation between the roughness and the type of machining (CD or VAD).

In addition to the surface roughness evaluation, the influence of the drilling processes on the interface zone between $\mathrm{C} 45 \mathrm{E}$ and CFRP was analysed. Figure 11 shows the cross sections of selected hole walls after drilling 160 holes. Again, the cutting speeds of 40 and $80 \mathrm{~m} / \mathrm{min}$ were used. At both cutting speeds CD shows some kind of burr formation, as steel material is pushed into the CFRP material area. It becomes obvious, that this effect can be avoided by drilling with vibration assistance.

Besides the aforementioned quality aspects, the damage mechanisms in CFRP are of particular interest. Thus delamination, fraying and splintering were analysed in detail. The

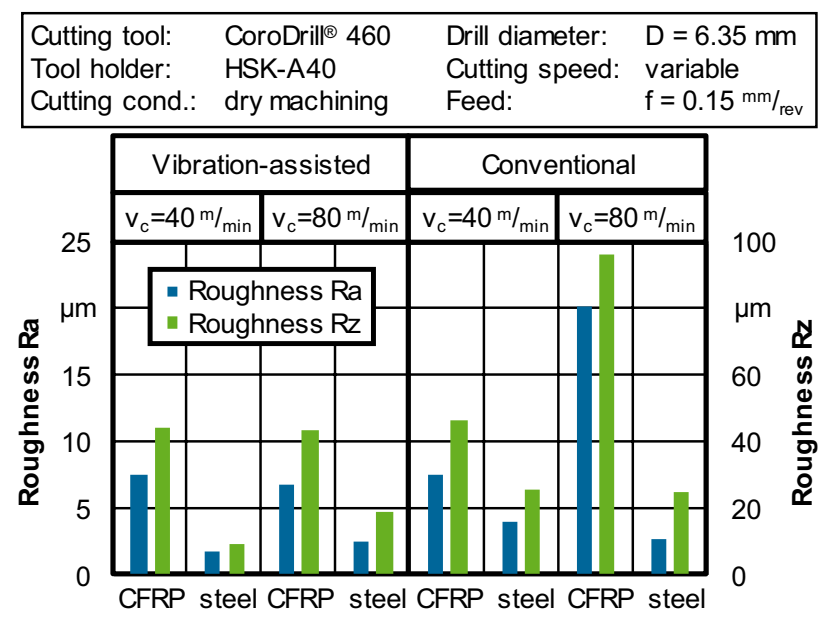

Fig. 10 Surface roughness of selected holes

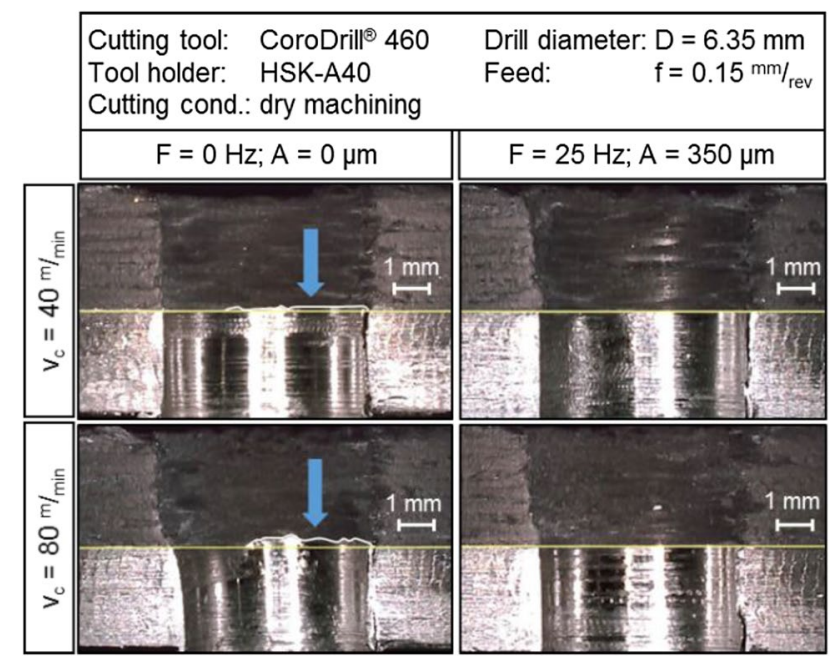

Fig. 11 Burr formation at the CFRP and metal interface

measuring process, according to [28, 29], starts with the evaluation of delamination (d), fraying (f) and splintering (s) caused by drilling. The maximum lengths of the occurring damages $\left(f_{\max }, d_{\max }, s_{\max }\right)$ were measured optically (cf. Fig. 12). Damage factors ( $f, d, s)$ for all occurring damages were calculated similar to Eq. (2).

$f=\frac{f_{\max }}{f_{\text {crit }}} \cdot 100 \mathrm{in} \%$

The maximum length of the damage is divided by a previously defined critical damage length, which was specified as the diameter $D_{0}$ of the drilled hole [29].

To characterise the machining quality with one single value, the quality index $q$ is defined by Eq. (3), which is the average of the three single damage values.

$q=\frac{d+f+s}{3}$

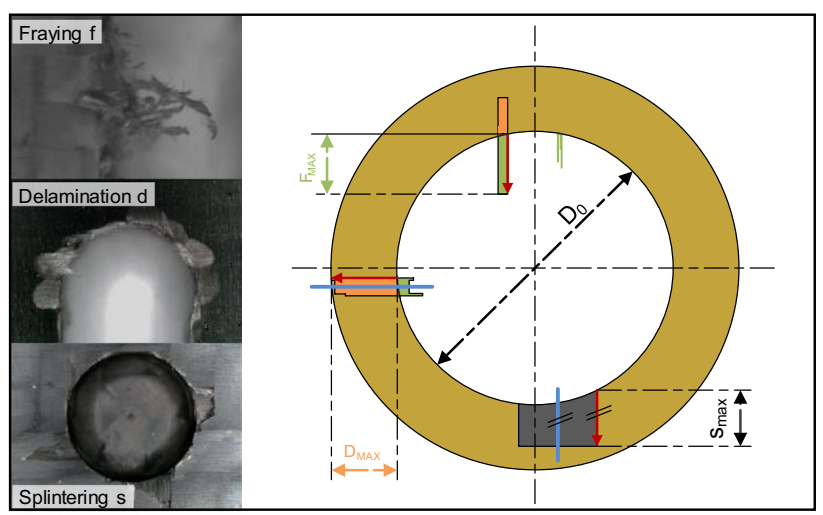

Fig. 12 Schematic illustration of possible defects [29] 
Table 1 Results of the quality evaluation for CFRP

\begin{tabular}{lcl}
\hline & Reference (\%) & VAD (\%) \\
\hline Quality index $q$ & 8.51 & 3.84 \\
Fraying $f$ & 0.52 & 0.06 \\
Delamination $d$ & 6.77 & 2.86 \\
Splintering $s$ & 18.23 & 8.60 \\
\hline
\end{tabular}

The possible range of the quality indices is between $0 \%$ (no measurable damage) and $100 \%$ (maximum damage length equals the critical damage length $D_{0}$ ). In order to evaluate the influence of VAD on the damage mechanisms in CFRP drilling tests using a cutting speed of $\mathrm{v}_{\mathrm{c}}=80 \mathrm{~m} /$ $\min$ and a feed of $\mathrm{f}=0.1 \mathrm{~mm} / \mathrm{rev}$ were conducted. During the reference tests no vibration assistance was applied. The VAD trials were done with a frequency of $\mathrm{F}=50 \mathrm{~Hz}$ and an amplitude of $A=130 \mu \mathrm{m}$. The quality evaluation results are listed in Table 1.

As it can be depicted, the quality indices for delamination, fraying and splintering decrease as a result of using VAD, which indicates a higher surface quality. The high splintering index without vibration assistance can be related to surface damages caused by the long steel chips which occur under these conditions (cf. Fig. 8).

\section{Conclusion}

For the machining of compound material made of $\mathrm{C} 45 \mathrm{E}$ and CFRP, the presented spindle unit with hydraulic actuator offers opportunities to improve the drilling process of stack material. Due to the vibration at low frequencies and high amplitudes, the chips are separated into small segments. This leads to a supported chip evacuation and thus, chip congestion can be avoided. Furthermore, the surface damage of splintering, which is also influenced by long chips, can be significantly reduced and a burr formation at the interface between steel and CFRP can be avoided. Additionally, the generation of smaller chips decreases the mechanical loads on the tool which results in a reduction of the feed force leading to significant improvement in the tool wear behaviour.

Acknowledgements Open access funding provided by TU Wien (TUW).

Open Access This article is distributed under the terms of the Creative Commons Attribution 4.0 International License (http://creativeco mmons.org/licenses/by/4.0/), which permits unrestricted use, distribution, and reproduction in any medium, provided you give appropriate credit to the original author(s) and the source, provide a link to the Creative Commons license, and indicate if changes were made.

\section{References}

1. Bonnet C, Poulachon G, Rech J, Girard Y, Costes JP (2015) CFRP drilling: fundamental study of local feed force and consequences on hole exit damage. Int J Mach Tools Manuf 94:57-64

2. Zitoune R, Krishnaraj V, Collombet F (2010) Study of drilling of composite material and aluminium stack. Compos Struct 92(5): 1246-1255

3. Pecat O, Brinksmeier E (2014) Tool wear analyses in low frequency vibration assisted drilling of CFRP/Ti6Al4V stack material. Proc CIRP 14:142-147

4. Zitoune R, Krishnaraj V, Sofiane Almabouacif B, Collombet F, Sima M, Jolin A (2012) Influence of machining parameters and new nano-coated tool on drilling performance of CFRP/Aluminium sandwich. Compos Part B Eng 43(3):1480-1488

5. Brinksmeier R, Janssen E (2002) Drilling of multi-layer composite materials consisting of carbon fiber reinforced plastics (CFRP), titanium and aluminum alloys. CIRP Ann Manuf Technol 51(1):87-90

6. Denkena B, Biermann D (2014) Cutting edge geometries. CIRP Ann Manuf Technol 63(2):631-653

7. Klocke F, Krieg T (1999) Coated tools for metal cutting-features and applications. CIRP Ann Manuf Technol 48(2):515-525

8. Kuo C, Li Z, Wang C (2017) Multi-objective optimisation in vibration-assisted drilling of CFRP/Al stacks. Compos Struct 173:196-209

9. Kim D, Ramulu M (2004) Drilling process optimization for graphite/bismaleimide-titanium alloy stacks. Compos Struct 63(1):101-114

10. Ramulu M, Branson T, Kim D (2001) A study on the drilling of composite and titanium stacks. Compos Struct 54(1):67-77

11. Sadek A, Attia MH, Meshreki M, Shi B (2013) Characterization and optimization of vibration-assisted drilling of fibre reinforced epoxy laminates. CIRP Ann Manuf Technol 62(1):91-94

12. Arola D, Ramulu M, Wang DH (1996) Chip formation in orthogonal trimming of graphite/epoxy composite. Compos Part A Appl Sci Manuf 27(2):121-133

13. Wang DH, Ramulu M, Arola D (1995) Orthogonal cutting mechanisms of graphite/epoxy composite. Part I: unidirectional laminate. Int J Mach Tools Manuf 35(12):1623-1638

14. Davim JP, Reis P, António CC (2004) Experimental study of drilling glass fiber reinforced plastics (GFRP) manufactured by hand lay-up. Compos Sci Technol 64(2):289-297

15. Piquet R, Ferret B, Lachaud F, Swider P (2000) Experimental analysis of drilling damage in thin carbon/epoxy plate using special drills. Compos Part A Appl Sci Manuf 31(10):1107-1115

16. Krishnaraj V et al (2012) Optimization of machining parameters at high speed drilling of carbon fiber reinforced plastic (CFRP) laminates. Compos Part B Eng 43(4):1791-1799

17. Sadek A, Aly M, Hamza K, Meshreki M, Nassef AO, Attia H (2015) Optimization of cutting conditions in vibration assisted drilling of composites via a multi-objective ego implementation. pp 1-9

18. Bleicher F, Kumpf C (2017) Schwingungsunterstützte Zerspanung. In: Spanende Fertigung 7, pp 37-47

19. Sadek A, Meshreki M, Attia MH (2014) Effect of tool kinematics on the drilling forces and temperature in low frequency high amplitude vibration assisted drilling. In: ASME 2014 international mechanical engineering congress and exposition, pp 1-7

20. Arul S, Vijayaraghavan L, Malhotra SK, Krishnamurthy R (2006) The effect of vibratory drilling on hole quality in polymeric composites. Int J Mach Tools Manuf 46(3-4):252-259

21. Ramkumar J, Aravindan S, Malhotra SK, Krishnamurthy R (2004) An enhancement of the machining performance of 
GFRP by oscillatory assisted drilling. Int J Adv Manuf Technol 23(3-4):240-244

22. Takeyama H, Kato S (1991) Burrless drilling by means of ultrasonic vibration. CIRP Ann Manuf Technol 40(1):83-86

23. Paris H, Tichkiewitch $\mathrm{S}$, Peigné G (2005) Modelling the vibratory drilling process to foresee cutting parameters. CIRP Ann Manuf Technol 54(1):367-370

24. Ding H, Ibrahim R, Cheng K, Chen SJ (2010) Experimental study on machinability improvement of hardened tool steel using two dimensional vibration-assisted micro-end-milling. Int J Mach Tools Manuf 50(12):1115-1118

25. Okamura K, Sasahara H, Segawa T, Tsutsumi M (2006) Lowfrequency vibration drilling of titanium alloy. JSME Int J Ser C 49(1):76-82
26. López N, De Lacalle A, Lamikiz FJ, Campa AF, Valdivielso, Etxeberria I (2010) Milling of carbon fiber reinforced plastics López. J Compos Mater 83-86:49-55

27. Verein Deutscher Ingenieure VDI (1990) Stahl-Eisen-Prüfblatt 1178-90 für die Klassifizierung von metallischen Spänen aus der mechanischen Bearbeitung. Verlag Stahleisen 8

28. DIN SPEC 25713:2017-02 (2017) Evaluation of the quality of machined parts made of fibre reinforced plastics. Beuth Verlag, Berlin, $\mathrm{p} 47$

29. Zemann R, Sacherl J, Hake W, Bleicher F (2015) New measurement processes to define the quality of machined fibre reinforced polymers. Proc Eng 100:636-645 